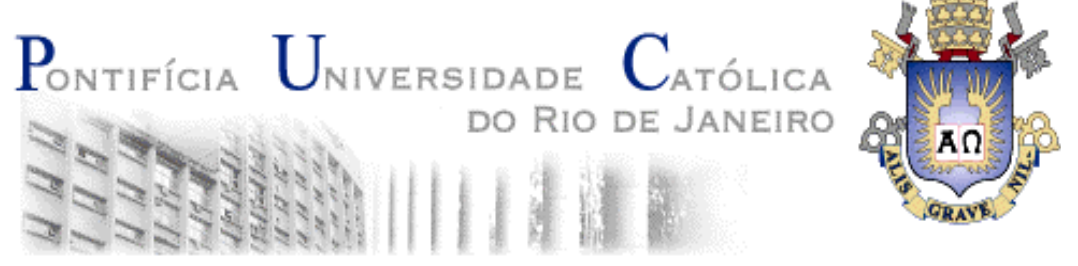

Janaina Barreto Santos

Estudo Experimental dos Mecanismos de Produção de Areia Empregando Tomografia Computadorizada de

Raios-X

Dissertação de Mestrado

Dissertação apresentada ao Programa de PósGraduação em Engenharia Civil da PUC-Rio como requisito parcial para obtenção do título de Mestre em Engenharia Civil da PUC-Rio. Área de Concentração: Geotecnia.

Orientadores: Eurípedes do Amaral Vargas Júnior Emílio Velloso Barroso 


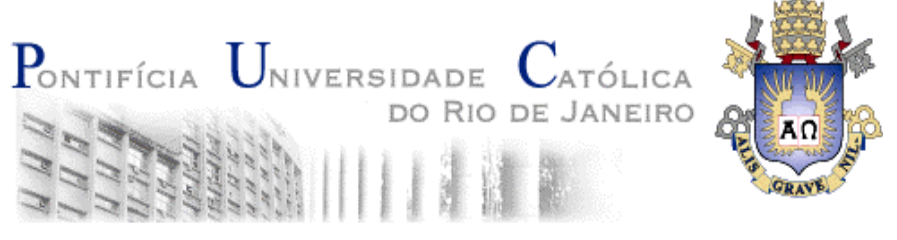

Janaina Barreto Santos

\title{
Estudo Experimental dos Mecanismos de Produção de Areia Empregando Tomografia Computadorizada de Raios-X
}

\begin{abstract}
Dissertação apresentada como requisito parcial para obtenção do título de Mestre pelo Programa de PósGraduação em Engenharia Civil da PUC-Rio. Aprovada pela Comissão Examinadora abaixo assinada.
\end{abstract}

Prof. Eurípedes do Amaral Vargas Júnior Orientador

Departamento de Engenharia Civil - PUC-Rio

Prof. Emílio Velloso Barroso

Co-Orientador IGEO/UFRJ

Prof. Franklin dos Santos Antunes Departamento de Engenharia Civil - PUC-Rio

Prof. Jaime Tupiassú Pinho de Castro Departamento de Engenharia Mecânica- PUC-Rio

Dr. Armando Prestes de Menezes Filho CENPES/PETROBRAS

Prof. Sérgio Augusto Barreto da Fontoura Departamento de Engenharia Civil - PUC-Rio

Prof. José Eugênio Leal Coordenador Setorial do Centro Técnico Científico - PUC-Rio 
Todos os direitos reservados. É proibida a reprodução total ou parcial do trabalho sem autorização da universidade, da autora e do orientador.

\section{Janaina Barreto Santos}

Graduada em Engenharia Civil pela UFV - Universidade Federal de Viçosa - MG, em 2001

Ficha Catalográfica

Santos, Janaina Barreto

Estudo Experimental dos Mecanismos de Produção de Areia Empregando Tomografia Computadorizada de RaiosX / Janaina Barreto Santos; Orientadores: Eurípedes do Amaral Vargas Jr; Emílio Velloso Barroso - Rio de Janeiro: PUC, Departamento de Engenharia Civil, 2004

$$
\text { v., } 142 f .: \text { il. ; } 29,7 \mathrm{~cm}
$$

Dissertação (mestrado) - Pontifícia Universidade Católica do Rio de Janeiro, Departamento de Engenharia Civil

Inclui referências bibliográficas.

1. Engenharia Civil - Teses. 2. Produção de areia. 3. Tomografia Computadorizada de Raios-X. 4. Mecanismos de ruptura. I. Vargas Jr., Eurípedes do Amaral. II. Barroso, Emílio Velloso. III. Pontifícia Universidade Católica do Rio de Janeiro. Departamento de Engenharia Civil. IV. Título. 


\section{Agradecimentos}

À Deus.

Aos meus orientadores, Prof. Vargas e Prof. Emílio, por todo suporte dado a este trabalho.

À minha amiga Eng. Sueli por sua dedicação e conhecimentos transmitidos.

À Elisabete Campos e André Tavares, do Laboratório de Tomografia Computadorizada de Raios-X do CENPES, pela atenção, carinho e pela disponibilidade de recursos imprescindíveis para a realização deste trabalho.

Aos funcionários do CENPES: Marcos Dantas, Rodrigo Barra, Clemente Gonçalves, Celso de Jesus Júnior, João Ribeiro, Júlio César Beltrami, Antônio Cláudio, Armando Prestes, Jacques Coelho, por cederem recursos fundamentais para esta pesquisa.

A todos os professores e funcionários do Departamento de Engenharia Civil da PUC-Rio e, em especial aos Prof. Franklin Antunes e Sérgio Fontoura pelo apoio e constante incentivo. Ao Professor Dr. Jaime Tupiassú Pinho de Castro do Departamento de Engenharia Mecânica da PUC-Rio.

Aos meus pais por todo o apoio e amor que me foram dados ao longo da minha vida.

Ao meu Amor, Rogério, pelo companheirismo.

Aos meus amigos e amigas pela solidariedade e otimismo e pela compreensão pelo meu afastamento nos últimos tempos.

A PUC e a CAPES pelos recursos financeiros a pesquisa.

Enfim, a todos que de uma forma ou de outra me ajudaram a chegar até aqui. 


\section{Resumo}

Santos, Janaina Barreto; Vargas Jr, Eurípedes do Amaral (orientador); Barroso, Emílio Velloso (co-orientador). Estudo Experimental dos Mecanismos de Produção de Areia Empregando Tomografia Computadorizada de Raios-X. Rio de Janeiro, 2004. 142p. Dissertação de Mestrado - Departamento de Engenharia Civil, Pontifícia Universidade Católica do Rio de Janeiro.

Durante a fase produtiva de um poço de petróleo ou gás, muitas vezes há a produção simultânea de partículas sólidas arrancadas da matriz da rocha reservatório. Este fenômeno recebe o nome de produção de areia. Neste caso as tensões e as condições de fluxo nas vizinhanças do poço são fatores fundamentais para a deflagração do processo. As tensões que se concentram na parede do poço com a perfuração do mesmo, pode ser de tal magnitude que pode causar a perda da coesão entre os grãos e criando , assim, uma região de material granular susceptível ao arraste pelas forças de percolação derivadas do fluxo.

Este trabalho visou a realização de ensaios em amostras de arenito Rio Bonito e arenito sintético utilizando a técnica da Tomografia Computadorizada de Raios-X para acompanhamento em tempo real dos ensaios. Os ensaios tiveram por objetivo identificar a pressão de início e o modo de propagação da ruptura da parede da cavidade interna da amostra ensaiada. Estes são estágios iniciais dos processos de produção de areia em rochas.

As análises das imagens tomográficas adquiridas durante os ensaios permitiram a visualização de breakouts e arrombamentos dos poços. Estudos mais detalhados possibilitaram estimar a quantidade de areia produzida e reconstruir tridimensionalmente o processo de propagação da ruptura.

\section{Palavras-chave}

Produção de areia; Tomografia Computadorizada de Raios-X; Mecanismos de ruptura. 


\section{Abstract}

Santos, Janaina Barreto; Vargas Jr., Eurípedes do Amaral (advisor); Barroso, Emílio Velloso (advisor). Experimental Study of Mechanisms of Sand Production Using X-Ray Computerized Tomography . Rio de Janeiro, 2004. 142p. MSc. Dissertation - Departamento de Engenharia Civil, Pontifícia Universidade Católica do Rio de Janeiro.

During productive phase of the well, manytimes there is simultaneous production of the solid particles detached from matrix of the reservoir rock. This phenomenon receive the name of the sand production. In this case stress and flow conditions around of the well are fundamental factors for deflagration of the process. Stress concentration in the wall of the well lead to the loss of cohesion between grains arising, consequently, a granular material region susceptible for dragging by seepage forces derived from fluid flow.

The objective of this work was to perform sand production tests in Rio Bonito and synthetic sandstone samples using real-time X-Ray Computerized Tomography. The tests investigated the initial and the evolution of failure at the cavity wall of samples. These are initial stages of the sand production process.

The analysis of the CT-scans obtained during tests allowed the visualization of breakouts and collapses of the wells. From studies more details were possible estimate the sand production and produce 3-D images of the propagation of the failure.

\section{Keywords}

Sand production; X-Ray Computerized Tomography; Failure mechanisms. 


\section{Sumário}

1. Introdução

$\begin{array}{ll}\text { 2. Produção de Areia } & 20\end{array}$

2.1. Principais Aspectos da Produção de Areia 20

2.2. Mecanismos da produção de areia 22

2.3. Estudos Experimentais de Simulação da Produção de Areia 25

3. Tomografia Computadorizada de Raios $-X \quad 37$

3.1. Fundamentos Teóricos Tomografia Computadorizada de Raios $X 37$

3.1.1. Geração de raios X e interação com a matéria: 37

3.1.2. Formação da Imagem 39

3.1.3. Unidades utilizadas em imagens tomográficas: 40

3.1.4. Escala de cores ou tons de cinza: 41

3.2. Utlização da Tomografia Computadorizada de Raios X em Rochas 42

4. Programa Experimental 58

4.1. Caracterização dos Arenitos 58

4.1.1. Arenito Rio Bonito 58

4.1.2. Arenito Sintético 70

4.2. Equipamentos Utilizados 72

4.2.1. Célula de Pressão 72

4.2.2. GDS $\quad 75$

4.2.3. Atuador Hidráulico Manual 76

4.2.4. Tomógrafo 76

4.3. Preparação dos Corpos de Prova 77

4.4. Metodologia de Ensaio 78

5. Resultados $\quad 85$

5.1. Primeira Metodologia (GDS) 85

5.2. Segunda Metodologia (Bomba Manual) 88

5.3. Terceira Metodologia (acréscimo de tensão axia) 101 
6. Conclusões e Sugestões para Trabalhos Futuros 136

6.1. Conclusões 136

6.2. Sugestões para Trabalhos Futuros 137

7. Referências Bibliográficas 138 


\section{Lista de Figura}

Figura 2.01 - Retração do cimento (Dusseault \& Santarelli,1989). 23

Figura 2.02 - Plastificação no canhoneamento (Dusseault \& Santarelli ,1989). 23

Figura 2.03 - Interior e subestrutura da célula de pressão desenvolvida para os experimentos de ruptura em cavidades com aplicação de fluxo (Tronvoll \& Fjaer,1994). 26

Figura 2.04 - Imagens de seções transversais de duas amostras após o ensaio:

(a) tamanho médio de grãos constituinte igual a $250 \mu \mathrm{m}, \mathrm{e}$ (b) $100 \mu \mathrm{m}$.

(Tronvoll et al.,1997) 28

Figura 2.05 - Seção ao longo do eixo axial do corpo de prova de arenito Red Wildmoor. As dimensões são dadas em milímetros (Unander et al,1997). 29

Figura 2.06 - Duas geometrias de fluxo: no caso axial, o fluido entra na amostra através do pistão perfurado do topo.O caso radial é obtido usando uma membrana com oito furos, sendo o fluido distribuído nos $2 / 3$ inferiores da amostra (Unander et al ,1997)

Figura 2.07 - Imagem tomográficas mostrando um padrão típico de dano criado em ambos os fluxos. À esquerda o dano causado pelo fluxo radial e à direita, pelo fluxo axial.(Unander et al ,1997)

Figura 2.08 - Imagens tomográficas representando como o fluxo de fluido remove o material rompido da cavidade. A amostra da esquerda foi ensaiada sem fluxo, enquanto a imagem a da direita foi ensaiada com fluxo radial. Os corpos de prova foram carregados radialmente no estado plano de deformação até 25,2 e 19,3 MPa, respectivamente (Unander et al,1997) 30

Figura 2.09 - Aparato experimental desenvolvido para ensaios de produção de areia em TWC (Papamichos ,1999).

Figura 2.10 - Imagens tomográficas de seções transversais de amostras ensaiadas.(a) Arenito Red Wildmoor; (b) Arenito Sintético; (c) Testemunho A;

(d) Testemunho B; e (e) Testemunho C. (Papamichos,1999). 
Figura 2.11 - Imagens tomográficas de seções transversais de amostras ensaiadas:.(a) Testemunho D, (b) Testemunho E, e (c) Testemunho F (Papamichos, 1999)

Figura 2.12 - Esquema do fluxo radial no ensaio de produção de areia com amostra de $200 \mathrm{~mm}$ de diâmetro externo (Vardoulakis et al, 2001).

Figura 2.13 - Total acumulado da produção de areia versus tensão externa (Vardoulakis et al, 2001).

Figura 2.14 - Total acumulado da produção de areia versus tempo com várias taxas de fluxo e pressão confinante igual a $11 \mathrm{Mpa}$ (Vardoulakis et al, 2001)

Figura 2.15 - Imagens tomográficas após o ensaio: (a) Seção longitudinal, (b) seção transversal do topo, (c) (meio) e (d) base do corpo de prova (Vardoulakis et al, 2001).

Figura 3.01.- Configuração do sistema de aquisição de imagens do tomógrafo 38

Figura 3.02.- Escala de cores (A) e de tonalidades de cinza (B).

Figura 3.03 - Evolução da invasão de fluido de perfuração durante um período de 10 horas. A região escura ao redor do poço indica que o fluido de saturação da rocha (alta densidade) é deslocado por uma solução menos densa que é o fluido de perfuração Os números indicam horas desde o início do ensaio.

Figura 3.04 - Exemplo de seções de uma amostra de arenito (à esquerda) e de siltito (à direita)

Figura 3.05 - Processo de saturação por água observado por imagens tomográficas. O avanço da região mais clara nas figuras representa o aumento da densidade pela invasão da água nos poros da rocha

45

Figura 3.06 - Imagens ao final dos ensaios de compressão triaxial em amostras de arenito saturadas com diferentes soluções aquosas ou no estado natural: (a) $\mathrm{NaCl} \mathrm{em} \mathrm{pH} \mathrm{7;} \mathrm{(b)} \mathrm{NaCl} \mathrm{em} \mathrm{pH} \mathrm{9;} \mathrm{(c)} \mathrm{NaCl} \mathrm{em} \mathrm{pH} \mathrm{12;} \mathrm{(d)} \mathrm{ar;} \mathrm{(e)} \mathrm{água} \mathrm{do}$ Rio Amarelo (China); (f) água destilada; (g) $\mathrm{CaCl}_{2} \mathrm{em} \mathrm{pH}$ 9; (h) $\mathrm{NaCl}$ em pH 2; e (i) $\mathrm{NaHCO}_{3}$ em pH 9.

Figura 3.07 - Posicionamento da célula triaxial na mesa do tomógrafo

Figura 3.08 - Imagem longitudinal do corpo de prova apresentando o plano de cortes. 
Figura 3.09 - Seções transversais do corpo de prova G-4 com tensão axial nula.49 Figura 3.10 - Seções transversais do corpo de prova G-4 com tensão axial de 2,5 MPa, após 15 minutos do início do ensaio. Notar início da ruptura nas três últimas seções.

Figura 3.11 - Seções transversais do corpo de prova G-4 com tensão axial de 3,3MPa, após 20 minutos do início do ensaio.

Figura 3.12 - Seções transversais do corpo de prova G-4 com tensão axial de 4MPa, após 25 minutos do início do ensaio.

Figura 3.13 -Piloto do corpo de prova G-4 com tensão axial nula. Através da tomografia pode-se observar o acamamento da amostra provocado pela confecção em camadas

Figura 3.14 - Piloto do corpo de prova G-4 com tensão axial de 2,8 MPa, após 17 minutos do início do ensaio. Observa-se início de fraturas se propagando a partir da região central do corpo de prova.

Figura 3.15 - Piloto do corpo de prova G-4 com tensão axial de 3,8 MPa, após 23 minutos do início do ensaio. Verifica-se a extensão da fratura central e aparecimento de outras na extremidade superior.

Figura 3.16 - Piloto do corpo de prova G-4 com tensão axial de $5 \mathrm{MPa}$, após 30 minutos do início do ensaio.

Figura 3.17 - Foto do corpo de prova G-4 antes do ensaio 55

Figura 3.18 - Foto do corpo de prova G-4 após o ensaio 55

Figura 3.19 - Instantâneo da reconstrução 3D no início do ensaio.

Figura 3.20 - Instantâneo da reconstrução 3D com tensão axial de 3,3 MPa, após 20 minutos do início do ensaio.

Figura 3.21 - Instantâneo da reconstrução 3D com tensão axial de $5 \mathrm{MPa}$, após 30 minutos do início do ensaio.

Figura 4.01 - Roteiro para confecção de lâminas delgadas impregnadas (Cesero et al.,1989).

Figura 4.02 - Visualização da amostra 697-RB aumentada 20 vezes.

Figura 4.03 - Visualização da região central da amostra 697-RB aumentada 100 vezes.

Figura 4.04 - Composição química do quartzo.

Figura 4.05 - Composição química do feldspato - potássico 
Figura 4.06 - Composição química da caulinita.

Figura 4.07 - Composição química do cimento silicoso 63

Figura 4.08 - Composição química do argilomineral amorfo 63

Figura 4.09 - Composição química do poro. Estes elementos fazem parte da composição química da resina araltide

Figura 4.10 - Contato entre grãos de feldspato com aumento de 2000 vezes 64

Figura 4.11 - Estrutura de um grão de caulinita com aumento de 3000 vezes da amostra 697-RB.

Figura 4.12 - Estrutura de um grão de feldspato com aumento de 3000 vezes da amostra 697-RB.

Figura 4.13 - Visualização da amostra 699-RB aumentada 20 vezes

Figura 4.14 - Visualização da região central da amostra 699-RB aumentada 100 vezes

Figura 4.15 - Composição química do titânio. Este, provavelmente foi transportado, devido a existência de pouquíssimos grãos.

Figura 4.16 - Estrutura de um contato entre grãos de caulinita (região mais escura) e feldspato com aumento de 3000 vezes da amostra da amostra 699-RB.

Figura.4.17 - Curva tensão x deformação axial da amostra 696-RB 68

Figura 4.18 - Projeto da célula de Pressão $\quad 73$

Figura 4.19 - Detalhe da câmara de tensão axial no projeto da célula 74

Figura 4.20 - Fotografia da célula. $\quad 75$

Figura 4.21 - Fotografia do controlador/atuador GDS 76

Figura 4.22 - Tomógrafo Médico $\quad 77$

Figura 4.23 - Corpos de prova após a perfuração: à esquerda arenito Rio Bonito e à direita arenito sintético

Figura 4.24 -Visão transversal dos corpos de prova: à esquerda arenito Rio Bonito e à direita arenito sintético

Figura 4.25 - Montagem do Corpo de prova. Os caps estão envolvidos com fita alta fusão.

Figura 4.26 - Soprador térmico e corpo de prova envolvido pela membrana termoretrátil 
Figura 4.28 - Amarração com arame

Figura 4.29 - Colocação do corpo de prova

Figura 5.23 - Seções transversais do corpo de prova 698-RB com pressão confinante e tensão axial nulas

Figura 5.24 - Seções transversais do corpo de prova 750-RB com pressão de confinante de $10 \mathrm{MPa}$ e tensão axial de $5 \mathrm{MPa}$

Figura 5.25 - Seções transversais do corpo de prova 750-RB com pressão de confinante de $15 \mathrm{MPa}$ e tensão axial de $5 \mathrm{MPa}$

Figura 5.26 - Seções transversais do corpo de prova 750-RB com pressão de confinante de $25 \mathrm{MPa}$ e tensão axial de $5 \mathrm{MPa}$.

Figura 5.27 - Seqüência da propagação da ruptura da seção a $23 \mathrm{~mm}$ : estágios 0 a 3

Figura 5.28 - Imagens Pilotos antes e após o ensaio

Figura 5.29 - Fotografia do corpo de prova 750-RB após o ensaio. Com o colapso global, a membrana foi danificada permitindo que o óleo contaminasse a amostra.

Figura 5.30 - Fotografia do corpo de prova 750-RB após o ensaio. Notar invasão de partículas para o interior da cavidade.

Figura 5.31 - Seções transversais do corpo de prova V5-2 com pressão confinante nula e tensão axial nula.

Figura 5.32 - Seções transversais do corpo de prova V5-2 com pressão de confinante de $20 \mathrm{MPa}$ e tensão axial de $10 \mathrm{MPa}$.

Figura 5.33 - Seções transversais do corpo de prova V5-2 com pressão de confinante de $30 \mathrm{MPa}$ e tensão axial de $12 \mathrm{MPa}$.

Figura 5.34 - Seções transversais do corpo de prova V5-2 com pressão de confinante de $40 \mathrm{MPa}$ e tensão axial de $5 \mathrm{MPa}$

Figura 5.35 - Subtração das imagens do corpo de prova V $5-2$ no estágio 0 menos as do estágio 6.

Figura 5.36 - Imagens Pilotos antes e após o ensaio

Figura 5.37 - Corpo de prova V5 -2 após o ensaio

Figura 5.38 - Corpo de prova V5-2 após o ensaio. Notar o preenchimento de toda a cavidade interna por material granular

Figura 5.39 - Seções transversais do corpo de prova V8-2 com pressão confinante nula e tensão axial nula 
Figura 5.40 - Seções transversais do corpo de prova V8-2 com pressão de confinante de $20 \mathrm{MPa}$ e tensão axial de $10 \mathrm{MPa}$

Figura 5.41 - Seções transversais do corpo de prova V8-2 com pressão de confinante de $25 \mathrm{MPa}$ e tensão axial de $12,5 \mathrm{MPa}$

Figura 5.42 - Seções transversais do corpo de prova V8-2 com pressão de confinante de $40 \mathrm{MPa}$ e tensão axial de $15 \mathrm{MPa}$.

128

Figura 5.43 - Visualização do material granular preenchendo a cavidade interna da figura 5.42

129

Figura 5.44 - Seqüência da propagação da ruptura da seção $32,5 \mathrm{~mm}$. Estágios de 0 a 6 .

130

Figura 5.45 - Subtração de imagens estágio 0 menos estágio 6 131

Figura 5.46 - Pilotos antes e após o ensaio do corpo de prova V8-2 133

Figura 5.47 - Corpo de prova V8-2 após o ensaio.

Figura 5.48 - Corpo de prova V8-2 após o ensaio. Notar o preenchimento de toda a cavidade interna por material granular (seta).

134

Figura 5.49 - Instantâneo da reconstrução 3D no início do ensaio 135

Figura 5.50 - Instantâneo da reconstrução 3D no estágio 5 135

Figura 5.51 - Instantâneo da reconstrução 3D no estágio 6 135 


\section{Lista de Tabelas}

Tabela 2.01 - Parâmetros que influenciam a produção de areia.

Tabela 2.02 - Produção de areia com fluxo radial. (Papamichos,1999) 32

Tabela 4.01 - Composição mineralógica do arenito Rio Bonito.(Barroso,2002) 60

Tabela 4.02 - Porosidade aparente das amostras de Rio Bonito 69

Tabela 4.03 - Porosidade aparente das amostras do Arenito Sintético. 71

Tabela 5.01 - Características dos corpos de prova 85

Tabela 5.02 - Características dos corpos de prova 88

Tabela 5.03 - Estágios de carregamento. $\quad 89$

Tabela 5.4 - Características dos corpos de prova 101

Tabela 5.05 - Estágios de carregamento 102

Tabela 5.06 - Estimativa da área do breakout e da quantidade de areia produzida para o corpo de prova 698 -RB 109

Tabela 5.07 - Estimativa da área do breakout e da quantidade de areia produzida para o corpo de prova V5-2. 122 Tabela 5.08 - Estimativa da área do breakout e da quantidade de areia produzida para o corpo de prova V8-2 